\title{
Percepção ambiental e revitalização de praça pública por meio da reutilização de resíduos sólidos (Jequié, Bahia, Brasil)
}

\section{Iran Santos Silva ${ }^{1}$, Valdirene Santos Rocha Sousa ${ }^{2}$ e Hélio Rocha Sousa Filho ${ }^{3}$}

${ }^{1}$ Instituto Federal de Educação Ciência e Tecnologia da Bahia. Curso de PósGraduando em Gestão e Educação Ambiental. Campus de Jequié. Rua John Kennedy, S/No. Jequié-BA, Brasil (CEP 45201-570) E-mail: iranssilvabio@gmail.com.

${ }^{2}$ Instituto Federal de Educação Ciência e Tecnologia da Bahia. Campus de Jequié. Rua John Kennedy S/№. Jequié-BA, Brasil (CEP45201-570).

${ }^{3}$ Universidade Estadual de Santa Cruz. Programa de Pós-Graduação em Meio Ambiente e Desenvolvimento. Campus Soane Nazaré de Andrade. Rodovia Jorge Amado, km 16. Salobrinho. Ilhéus-BA, Brasil (CEP 45662-900).

Resumo. 0 crescimento nas taxas de produção de resíduos sólidos é algo preocupante, ainda mais se associado à falta de consciência ambiental da sociedade. No Município de Jequié, Estado da Bahia, Brasil, tem ocorrido ações de comunidades que residem nas proximidades de praças públicas, visando a reaproveitar resíduos sólidos para organização e conservação desses espaços. Este estudo objetivou conhecer a percepção ambiental da comunidade em torno de uma praça pública que foi revitalizada utilizando resíduos sólidos. A área de estudo foi ao redor da Praça da Amizade, localizada no Bairro Jequiezinho, em Jequié. A metodologia abarcou levantamento e análise de literatura especializada sobre o tema, observação in loco, aplicação de questionários e entrevistas. Os resultados evidenciaram que a percepção ambiental da comunidade é heterogênea, podendo ser associada aos paradigmas ambientais do antropocentrismo, ecocentrismo e, sobretudo, sustentabilidade-centrismo. Essa experiência de reaproveitamento dos resíduos sólidos demonstrou densidade, mobilização, participação social e continuidade ao longo do tempo. Os moradores em torno da praça apresentaram maior conhecimento da ação e sentido de pertencimento, se comparado aos moradores situados nas adjacências. A ação de revitalização foi unilateral pela comunidade, o que sugere ausência de governança ambiental. Neste ponto, suscitam-se investigações científicas que contemplem essa questão. Deste modo, a experiência de reaproveitar os resíduos sólidos por essa comunidade foi uma ação relacionada com a percepção ambiental e capaz de envolver os moradores no cuidado com o espaço público.
Recebido

$29 / 06 / 2021$

Aceito

$27 / 08 / 2021$

Publicado

$31 / 08 / 2021$

Acesso aberto

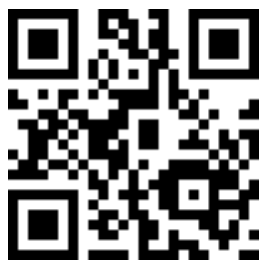

ORCID

(D) 0000-0003-0944-6773 Iran Santos Silva

(D) 0000-0002-1235-811X Valdirene Santos Rocha Sousa

D 0000-0002-2916-2084 Hélio Rocha Sousa Filho

ISSN 2359-1412/RBGAS-2021-0080/2021/8/19/34/1137

Rev. Bras. Gest. Amb. Sustent.

http://revista.ecogestaobrasil.net 
Palavras-chave: Paradigmas ambientais; Participação social; Praças públicas; Sustentabilidade.

\begin{abstract}
Reuse of solid waste and environmental perception of a public square (Jequié, Bahia, Brazil). The growth in solid waste production rates is something of concern, even more so if associated with society's lack of environmental awareness. In the Municipality of Jequié, State of Bahia, Brazil, actions have been taken by communities living in the vicinity of public squares, aiming to reuse solid waste for the organization and conservation of these spaces. This study aimed to understand the environmental perception of the community around a public square which was revitalized using solid waste. The study area was around Praça da Amizade, located in the Jequiezinho Neighborhood, in Jequié. The methodology included a survey and analysis of specialized literature on the subject, on-site observation, application of questionnaires and interviews. The results showed that the community's environmental perception is heterogeneous and may be associated with the environmental paradigms of anthropocentrism, ecocentrism and, above all, sustainability-centrism. This experience of reusing solid waste showed density, mobilization, social participation and continuity over time. Residents around the square showed greater knowledge of the action and sense of belonging, compared to residents located in the vicinity. The revitalization action was unilateral by the community, which suggests an absence of environmental governance. At this point, scientific investigations that address this issue are raised. Thus, the experience of reusing solid waste by this community was an action related to environmental perception and capable of involving residents in caring for the public space.
\end{abstract}

Keywords: Environmental paradigms; Social participation; Public squares; Sustainability.

\title{
Introdução
}

Os crescentes debates e estudos relacionados às problemáticas ambientais, que se sobrepõem, geralmente relacionadas aos impactos provocados por atividades antrópicas, podem contribuir para que a população repense seus hábitos. No que diz respeito ao descarte inadequado de resíduos sólidos, crescimento do consumo de produtos com embalagens descartáveis e emissões de gases poluentes na atmosfera, diversas pesquisas tem alertado para a gravidade dessas questões, tendo em vista a deterioração dos ecossistemas naturais (ABRELPE, 2017).

De acordo com a Política Nacional de Resíduos Sólidos (PNRS) (Lei no 12.305/2010) resíduo sólido é todo material, substância, objeto ou bem descartado resultante de atividades humanas em sociedade, estes resíduos podem ser oriundos tanto das atividades domésticas, quanto sociais e industriais, nos estados sólidos, semi-sólidos, bem como, gases e líquidos contidos em recipientes (Brasil, 2010). Esses resíduos, quando descartados de maneira inadequada, podem causar uma série de socioambientais, pois, 
dadas suas particularidades, torna-se inviável o seu lançamento na natureza sem o devido manejo.

Na sociedade moderna, segundo Cabral et al.(2016), a descartabilidade tem sido característica dos seres humanos e das relações que eles estabelecem entre si, seguindo a lógica na qual estão inseridos: consumir. 0 atual modelo de desenvolvimento social enfrenta duas problemáticas catalisadoras da degradação ambiental: o consumo desenfreado proposto pelo capitalismo e o descarte inadequado de resíduos gerados pelo consumo desgovernado, que tem acarretado o aumento nos níveis de degradação ao longo dos anos.

Conforme a Associação Brasileira de Empresas de Limpeza Pública e Resíduos Especiais (ABRELPE, 2017), até o ano de 2017 foram produzidas cerca de 43.945 t de resíduos sólidos recicláveis por dia no Brasil e desse total cerca de 13.969 toneladas foram recuperadas. Os dados de 2018 revelam que foram geradas 79 milhões de toneladas de resíduos, um aumento de pouco menos de $1 \%$ em relação ao ano anterior. Desse montante, cerca de 92\% (72,7 milhões) foram coletados, um aumento de 1,66\% em comparação a 2017 (ABRELPE, 2019). Até o ano de 2007 o Município de Jequié produzia cerca de 90 to/dia de lixo, das quais apenas 5\% eram direcionadas para reciclagem (Cunha et al., 2008).

Diante dessa realidade, surge a política dos 5 Rs (repensar, recusar, reduzir, reutilizar e reciclar), que, de acordo com o Ministério do Meio Ambiente (MMA, 2010), faz parte de um processo educativo que objetiva uma mudança de hábitos no cotidiano dos cidadãos e contribuem para a solução de problemas ambientais relacionados ao consumo de produtos que gerem impactos socioambientais significativos.

Esses problemas tendem a se agravar quando associados a um planejamento urbano falho ou inexistente, práticas rudimentares de descarte,ausência de tratamento de resíduos e falta de investimento em programas educacionais. 0 investimento em educação ambiental visa a uma mudança de atitude da população e dos gestores, a fim de pensar as problemáticas ambientais através da participação coletiva, com vistas ao estabelecimento de uma governança ambiental. Esta, na visão de Jacobi e Sinisgalli (2012), se pauta no envolvimento de todos e cada um dos agentes sociais nas decisões sobre o meio ambiente, por meio das organizações civis e governamentais, a fim de obter adesão ao projeto de manter a integridade do planeta.

Baseado no exposto, esse estudo pautou-se na inquietação desencadeada da observação cotidiana, em diferentes espaços públicos do Município de Jequié-BA. Notou-se que algumas praças públicas foram reorganizadas através do reaproveitamento de materiais que geralmente são descartados, quais sejam, resíduos sólidos. Os processos de revitalização de praças deram-se através da mobilização das comunidades que residem em torno desses espaços. Logo, surge a questão que delineia esse estudo: Quais os paradigmas ambientais presentes na percepção da comunidade residente em torno da Praça da Amizade, em Jequié, que foi recuperada através do reaproveitamento de resíduos sólidos?

Os paradigmas são expressos cotidianamente na forma como os seres humanos percebem o ambiente a sua volta, ou seja, veem, agem, ouvem ou sentem. Nessa perspectiva, a percepção ambiental pode ser concebida como uma tomada de consciência do ambiente pelo homem, ou seja, o ato de perceber o ambiente que se está inserido, aprendendo a proteger e a cuidar do mesmo. Cada indivíduo percebe, reage e responde diferentemente às ações sobre o ambiente em que vive, conforme propõem Panquestor e Ranguetti (2008).

Para tanto, aborda-se os paradigmas ambientais a partir da classificação proposta por Silva (2014, p. 2-6), que define três paradigmas de acordo com suas especificidades e linhas de raciocínio, antropocentrismo, ecocentrismo e sustentabilidade-centrismo. A abordagem antropocêntrica tem como ideia central a superioridade do ser humano, de

Rev. Bras. Gest. Amb. Sustent., 2021, vol. 8, n. 19, p. 1137-1153. 
modo que a natureza somente seja valorizada de um ponto de vista instrumental; a linha ecocêntrica defende o valor intrínseco das outras formas de vida, independentemente do seu interesse para a espécie humana e defende o valor não instrumental dos ecossistemas e da ecosfera, cujo equilíbrio pode obrigar a limitar determinadas atividades humanas; a sustentabilidade-centrista superar a dicotomia humanidade/natureza, predominante nos dois primeiros, destacando a noção de sustentabilidade a partir de uma nova perspectiva de que não somente o desenvolvimento deve ser sustentável, mas todas as ações humanas, tanto em seus fins, como em seus meios.

As praças podem ser consideradas elementos fundamentais da estrutura morfológica e social urbana. Segundo Carneiro (2004), podem ser conhecidas como espaços livres públicos, são caracterizadas por possuírem áreas vegetadas, livres de edificações ou parcialmente edificadas. Dentre suas funções primordiais, podem ser elencadas: circulação, lazer, recreação, composição paisagística e com importante função no equilíbrio ambiental urbano.

De acordo com Marchi e Pezzini (2015), por volta do século XVIII os projetos ou modelos de praças estavam ligados aos palácios europeus e estes nem sempre associados ao contexto urbano, enquanto que os espaços urbanos com grandes aglomerações humanas, que viriam a se tornar praças mais tarde, estavam relacionadas à presença de mercados populares, igrejas e catedrais. Somente no século XIX a praça passa a ser pensada como espaço de convivência e lazer, ideias que se concretizaram com a criação do Central Park, em Nova York. Com o passar do tempo esses espaços foram perdendo a essência como ambientes de convívio. Segundo Martins et al. (2014) atualmente pode-se observar que as praças não apresentam mais o mesmo impacto social como em tempos passados, pois antigamente esses lugares eram o centro dos acontecimentos políticos, das festividades, de atos cívicos e sociais, além de importantes ambientes de lazer.

De acordo com Sousa et al. (2016), as praças públicas são importantes para o equilíbrio urbano e a sua conservação por parte dos usuários e poder público são essenciais para a manutenção de seus serviços urbanos e ambientais. Contudo, a percepção ambiental da comunidade, sobretudo da população residente em volta desses espaços praça influencia diretamente na sua manutenção. Segundo Palma (2005), a influência do modelo atual de civilização fez com que o homem se desvinculasse do seu meio natural. Este desconhecimento e distanciamento são responsáveis pela dificuldade na percepção de sua atitude ou ação sobre a natureza.

Genericamente, pode-se definir percepção como o ato de notar, observar ou sentir algo, através dos sentidos olfato, tato, paladar, audição e visão. Por meio desses sentidos busca-se apreender o mundo à nossa volta. Contudo, a percepção não é a mesma para todas as pessoas, pois, cada indivíduo percebe e interage com o mundo conforme as suas necessidades e experiências.

Para Merleau-Ponty (1999) a experiência perceptiva é do tipo corporal e funda-se na vivência do sujeito encarnado, daquele que olha, sente e reconhece o espaço como expressivo e simbólico. Assim, a percepção é a instância que nos coloca em contato com o mundo e "nós acreditamos saber muito bem o que é "ver", "ouvir", "sentir", porque há muito tempo a percepção nos deu objetos coloridos ou sonoros" (Merleau-Ponty, 1999, p.25). Tuan (1980) também destaca a relação entre os sentidos e a percepção do indivíduo diante o espaço vivido. Para o autor,

Percepção é tanto uma resposta dos sentidos aos estímulos externos, como a atividade proposital, na qual certos fenômenos são claramente registrados, enquanto outros retrocedem para a sombra ou são bloqueados. Muito do que percebemos tem valor para nós, para a sobrevivência biológica, e para propiciar algumas satisfações que estão enraizadas na cultura (Tuan, 1980, p. 4). 
A percepção apresenta-se como um processo ativo da mente juntamente com os sentidos, ou seja, há uma contribuição da inteligência no processo perceptivo, que é motivada pelos valores éticos, morais, culturais, julgamento, experiências e expectativas daqueles que o percebem (Melazo, 2005). De acordo com Palma (2005), para perceber algo é necessário ter interesse no objeto de percepção, e esse interesse se baseia no conhecimento, na ética e na postura individual. Desta forma, mesmo convivendo em sociedade, cada ser humano tem uma percepção diferente do meio em que está inserido, baseada nas suas experiências e vivências. A percepção está ligada a subjetividade e desejo humano. Nesse sentido, a sociedade percebe o ambiente a sua volta, projetando sobre ele suas opiniões, desejos, insatisfações e expectativas.

Pacheco e Silva (2006) salientam que o estudo da percepção ambiental é relevante para que se possam compreender melhor as interrelações entre o homem e o ambiente, suas expectativas, julgamentos e condutas. Assim, o principal aspecto da percepção ambiental é a questão das relações entre o homem e o ambiente, como cada indivíduo o percebe, o quanto conhece do seu próprio meio, o que espera do seu meio e como o utiliza e sua ação cultural sobre esse meio (Cunha e Leite, 2009).

Algumas pessoas apresentam um olhar mais preservacionista com relação à natureza, outras apresentam uma visão antropocêntrica na qual a natureza e tudo que provém é entendido a partir de um olhar utilitarista, a partir do qual os recursos da natureza devem servir às necessidades dos seres humanos. Esses diferentes pontos de vista, além de outros, se relacionam com as diferentes visões de mundo, de sociedade, com o contexto social e cultural no qual as pessoas estão inseridas.

A forma como cada comunidade ou indivíduo interage com o meio pode se relacionar com as perspectivas e compreensões compreendidas no âmbito de diferentes paradigmas ambientais. Silva (2011) propõe a classificação desses paradigmas a partir de três tendências teóricas, a saber: o antropocentrismo, o ecocentrismo ou biocentrismo e, a sustentabilidade-centrismo. 0 antropocentrismo e o ecocentrismo se subdividem em individualistas e coletivistas de acordo com intenções ou interesses dos atores sociais.

No antropocentrismo o foco de todos os cuidados é o ser humano, ou seja, está pautado na superioridade humana, de forma que o mesmo é colocado como superior a toda forma de vida. De acordo com o antropocentrismo a natureza tem valor segundo as necessidades humanas, sendo que a preservação da mesma está em segundo plano. 0 ecocentrismo tem foco nos cuidados a toda forma de vida não humana e nos ecossistemas. Nessa corrente de pensamento o ambiente deve ser protegido por sua própria importância na manutenção de todas as formas de vida, e não por seus benefícios aos humanos (Abreu e Bussinguer, 2013). Apresenta-se um esforço de síntese, na tentativa de evidenciar as principais características de cada paradigma ambiental apresentado (Tabela 1), construído com base nas ideias de Silva et al. (2011).

0 antropocentrismo coletivista não apresenta preocupações com a natureza, mas compartilha preocupações com a humanidade como um todo, tendo a solidariedade com outros seres humanos como uma característica importante, enquanto que 0 antropocentrismo individualista não se preocupa com a humanidade de forma geral, ela se baseia em pressupostos egoístas por representar os interesses de um grupo distinto e restrito (Silva, 2014). 0 ecocentrismo coletivista defende que todas as formas de vida não humanas devem ser respeitadas e possuem valor, se preocupando, desta forma, com o ecossistema e não com grupos específicos. Já no ecocentrismo individualista, há uma preocupação com a natureza, no entanto essa se limita a grupos específicos. 0 preservacionismo é mais expressivo no primeiro caso do que o segundo Silva (2014). De acordo com Silva (2011), a sustentabilidade-centrismo parte da ideia de que humanidade e natureza estão integradas, e não se deve analisá-las como categorias distintas e independentes, pois a humanidade é parte da natureza. Esse modo de pensamento torna a 
sustentabilidade-centrismo mais próxima da visão ecocêntrica coletivista do que dos demais paradigmas ambientais.

Tabela 1. Classificação e sistematização de três paradigmas ambientais.

\begin{tabular}{|c|c|c|}
\hline Antropocentrismo & Ecocentrismo & $\begin{array}{l}\text { Sustentabilidade- } \\
\text { centrismo }\end{array}$ \\
\hline $\begin{array}{l}\text { O ser humano: A ideia central é } \\
\text { a superioridade humana. }\end{array}$ & $\begin{array}{l}\text { O ser humano: A humanidade não } \\
\text { ocupa lugar privilegiado na } \\
\text { Natureza. }\end{array}$ & $\begin{array}{l}\text { O ser humano: A humanidade } \\
\text { como parte da Natureza - } \\
\text { integração. }\end{array}$ \\
\hline $\begin{array}{l}\text { A Natureza: Vista como um } \\
\text { recurso econômico. } \\
\text { humanidade preserva a } \\
\text { natureza, para seu próprio } \\
\text { benefício, o interesse estaria } \\
\text { voltado à manutenção da } \\
\text { qualidade de vida humana e a } \\
\text { sua existência. A Natureza é } \\
\text { vista como instrumento e os } \\
\text { recursos naturais seriam } \\
\text { inexauríveis. }\end{array}$ & $\begin{array}{l}\text { A Natureza: E tudo que nela } \\
\text { existe, possui valor intrínseco. Os } \\
\text { recursos naturais deveriam ser } \\
\text { utilizados apenas para satisfazer } \\
\text { necessidades de subsistência, } \\
\text { preservando a integridade e a } \\
\text { estabilidade da biota. Defende o } \\
\text { valor não instrumental dos } \\
\text { ecossistemas e da ecosfera. }\end{array}$ & $\begin{array}{l}\text { A Natureza: Toda a ação } \\
\text { humana afeta a natureza, } \\
\text { mesmo que de forma } \\
\text { indireta, assim como todo o } \\
\text { fenômeno natural acaba por } \\
\text { afetar a humanidade de } \\
\text { alguma forma. Mútua } \\
\text { dependência entre a } \\
\text { humanidade a Natureza. }\end{array}$ \\
\hline $\begin{array}{l}\text { O planeta: Inerte e passivo, e, } \\
\text { por isso, sua exploração seria } \\
\text { legítima. }\end{array}$ & $\begin{array}{l}\text { O planeta: Vivo, ativo, frágil e } \\
\text { sagrado. }\end{array}$ & $\begin{array}{l}\text { O planeta: Finito e impactado } \\
\text { por atividades antrópicas } \\
\text { que têm alterado seus ciclos } \\
\text { biogeoquímicos. }\end{array}$ \\
\hline
\end{tabular}

Fonte: Silva et al. (2011).

A Política Nacional de Resíduos Sólidos (PNRS), ao centrar-se do discurso da sustentabilidade, ressalta no art. 25 que o poder público, o setor empresarial e a coletividade são responsáveis pela efetividade das ações voltadas para assegurar a observância da Política Nacional de Resíduos Sólidos e das diretrizes e demais determinações estabelecidas nesta Lei e em seu regulamento (Brasil, 2010). Até o presente momento (junho de 2021), o Município de Jequié ainda não dispunha de uma Política Municipal de Resíduos Sólidos. Diante desse contexto, este trabalho objetivou conhecer a percepção ambiental da comunidade em torno de uma praça pública da cidade de Jequié, que foi revitalizada utilizando resíduos sólidos, através da mobilização da população que residente ao redor desse espaço.

\section{Metodologia}

Trata-se de um estudo de caso, de natureza exploratória e abordagem qualitativa. A área de estudo selecionada foi a Praça da Amizade, situada na Urbis I, Bairro Jequiezinho, Jequié, Bahia. A Urbis I é dividida em dois setores censitários, de acordo com a classificação do Instituto Brasileiro de Geografia e Estatística (IBGE, 2010). 0 primeiro setor, número 291800105000065, nomeado neste trabalho como setor A, e o segundo, número 291800105000066, aqui denominado setor B.

Esta pesquisa foi realizada entre os anos de 2019 e 2021. Foram realizadas observação in loco, periodicamente, e registros fotográficos da área de estudo, levantamento e identificação dos agentes responsáveis pela mobilização da comunidade no processo de recuperação da praça. Realizaram-se também entrevistas 
semiestruturadas com as lideranças locais e entrevistas informais com pessoas que transitavam pela praça durante as observações in loco. As entrevistas abordaram pontos sobre o processo de organização da praça ao longo do tempo, com questões relativas à motivação, iniciativa, mobilização, objetivos e dificuldades encontradas durante o percurso de desenvolvimento do projeto.

A maioria das entrevistas e questionários foi realizada por meio das plataformas virtuais do Google Forms e Google Meet, e algumas de modo presencial, atentando para os protocolos de segurança recomendados pela Organização Mundial da Saúde (OMS). Para preservação da identidade dos colaboradores, os participantes da pesquisa foram identificados por letras maiúsculas do alfabeto, referentes às inicias dos seus nomes. Os questionários foram aplicados a moradores residentes em torno da praça e adjacências. No setor A e B foram identificados 554 e 491 moradores, respectivamente, totalizando 1.045 moradores acima de 15 anos (IBGE, 2010). A amostra foi composta por esse público, definindo-se estatisticamente um nível de confiança de 90\% e margem de erro de $10 \%$, para uma amostra mínima de 61 respostas ao questionário, obtendo-se 63 repostas. A análise do conteúdo se deu a partir de categorização, conforme proposto por Bardin (1997).

\section{Resultados e discussão}

Através do estudo de campo exploratório, no ano de 2019, foram identificadas cinco praças públicas no Bairro do Jequiezinho, nas quais se constata a presença de projetos liderados pelas comunidades no sentido de revitalizar esses espaços públicos. Nesse processo de qualificação, conforme já evidenciado, a comunidade utiliza materiais provenientes de descarte, resíduos sólidos, reaproveitando-os para a construção de brinquedos, canteiros de plantas, decoração, entre outros.

\section{Perfil socioeconômico dos participantes}

No que tange à variável "proximidade", nota-se que a maioria dos participantes, $(84,1 \%)$, moram atualmente na Urbis I, destes, $20,6 \%$ corresponde a população residente em torno da praça, no caminho D $(9,5 \%)$, caminho C $(9,5 \%)$ e caminho $S(1,6 \%)$ que são as ruas mais próximas à Praça da Amizade. Assim, destaca-se a relação direta com o espaço da vida cotidiana, a partir do qual a percepção dos sujeitos a respeito desses espaços vividos se constrói (Tuan, 1988; Merleau-Ponty, 1999). Os outros 16\% não residem no bairro, mas costumam visitar ou conhecem a praça.

Quanto ao modo de ocupação das residências, 61,9\% das pessoas habitam na condição de inquilinas, enquanto que 39,7\% são proprietárias dos imóveis. Esse processo pode estar associado ao fato de o bairro ter se tornado um bairro universitário ao longo do tempo, com a presença de muitos imóveis para fins de locação/aluguel. Característica devida à proximidade com Universidade Estadual do Sudoeste da Bahia (UESB). A ocupação e escolaridade do público pesquisado podem ser reforçados pela proximidade da Universidade, pois $31,4 \%$ das pessoas que compõem essa pesquisa são estudantes, $57,1 \%$ se encontram na faixa etária de 20 a 29 anos. No que concerne ao aspecto vínculo temporal, um terço $(33,3 \%)$ dos participantes afirmou residir no bairro há mais de 20 anos. Entretanto, a maioria $(44,4 \%)$ está estabelecida no local num período entre dois a cinco anos.

Destaca-se o elevado nível de escolarização dos respondentes, pois, a grande maioria, 84,2\%, já concluiu ou está cursando o ensino superior, destes, 22,3\% possuem cursos de pós-graduação (especialização, mestrado ou doutorado). Esse aspecto também pode ser relacionado com a proximidade geográfica entre a Praça da Amizade e a UESB.

No que diz respeito a variável renda familiar, nota-se uma realidade heterogênea. A maioria dos respondentes, $(44,4 \%)$, situam-se na faixa de renda entre 1 a 3 salários 
mínimos, enquanto $22,2 \%$ possuem renda entre 3 a 6 salários e apenas 3,2\% apresentam renda superior a 6 salários mínimos.

\section{Reaproveitamento de resíduos sólidos na Praça da Amizade}

No ano de 2014, um grupo de moradores, mobilizados através da liderança de duas moradoras, uma bióloga e uma pedagoga, começaram a reorganizar a Praça da Amizade. Segundo as líderes foram necessárias várias reuniões para organizar o projeto. Os moradores fizeram campanhas com o intuito de arrecadar fundos e mutirões para execução do projeto. De acordo com uma das lideranças foi um longo processo até que a praça alcançasse o estágio atual (Figura 1):

CS.: "Foi um trabalho árduo, você está aqui agora, no espaço todo prontinho né? Todo arborizado, organizado, limpo e aconchegante. Isso é bom a gente falar, mas até chegar a esse ponto era um espaço que estava todo degradado".
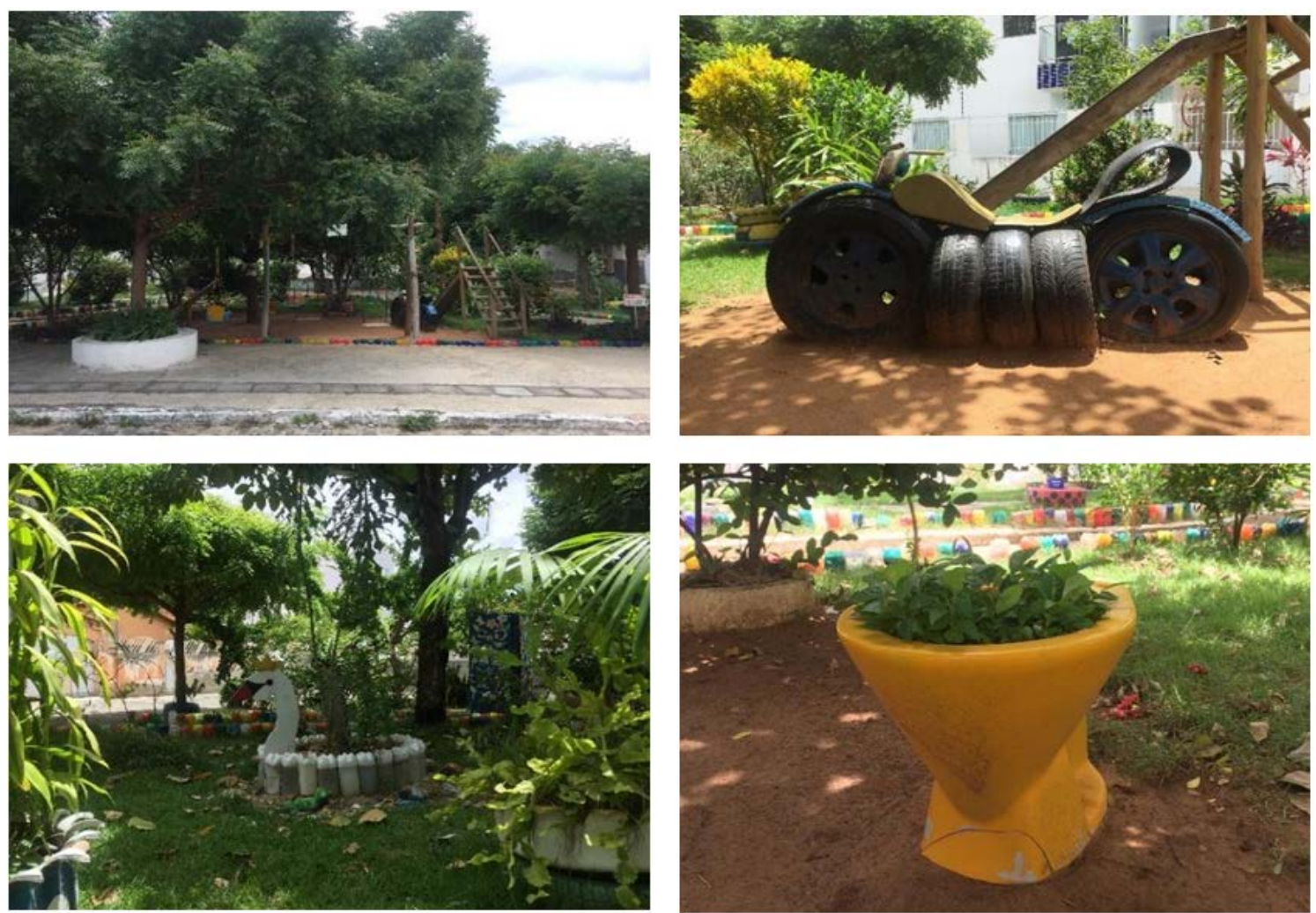

Figura 1. Praça da Amizade: reutilização de materiais recicláveis. 2021.

Os materiais reaproveitados com maior frequência na Praça da Amizade são pneus (para confecção de canteiros, balanços, enfeites, cercas, entre outros), garrafas pet's (utilizadas para ornamentação e construção de canteiros), restos de madeira e canos de PVC. Porém, outros materiais também são reutilizados, em menor quantidade, principalmente para servir de vasilhames para plantio e decoração. Cardoso e Souza (2020) ressaltam que a Praça da Amizade é um espaço transformado em um território 
lúdico e educativo. Esse espaço plural e singular ao mesmo tempo, apresenta infinitas possibilidades de estudo, interação e tem se tornado um espaço modelo para o município.

Como destaca Merleau-Ponty (1999), a percepção é atravessada por elementos diversos que afetam a maneira como cada pessoa percebe e se posiciona a respeito dos fenômenos que compõem suas existências. No que se refere à percepção ambiental relativa à Praça da Amizade, nota-se posicionamentos heterogêneos. Essa dissimilaridade é evidenciada a partir das relações que as pessoas estabelecem com o ambiente, a forma como cada indivíduo percebe e interage com a praça, interferindo assim na frequência que eles frequentam a praça, na gestão e cuidado com aquele ambiente.

Em relação à frequência de visitação, evidencia-se que o projeto de requalificação surtiu um efeito positivo, pois $61,9 \%$ dos participantes da pesquisa afirmaram não frequentar a praça antes do projeto, enquanto que 38,1\% já frequentavam antes da praça ser reorganizada pela comunidade. Sendo que antes do projeto, $65,1 \%$ não frequentavam, $12,7 \%$ visitavam até duas vezes na semana, $12,7 \%$ frequentava mais de quatro vezes na semana e 9,5\% das pessoas, só aos finais de semana. Após a realização do projeto a frequência se alterou, pois, cerca de $50,8 \%$ das pessoas passaram a frequentar a praça (raramente), 23,8\% frequentam diariamente, 17,5\% frequentam aos finais de semana e $7,9 \%$ nunca frequentou.

Contudo, é importante também levar em consideração o fato de que boa parte dos participantes da pesquisa é composta por população flutuante, que segundo Godinho (2008), é uma população que se estabelece em uma área por um período determinado de tempo. Ressalta-se novamente que $44,4 \%$ dos respondentes residem no bairro há apenas 2 a 5 anos, e 9,5\% moram no bairro a cerca de um ano e $25,4 \%$ da amostra foi composta por estudantes, no que compete a variável ocupação. Nesse sentido, tanto a análise da percepção quanto ao uso desse espaço público precisa ser considerada a partir dessa realidade.

Sobre a interação com o projeto de qualificação da praça, 74,6\% afirmaram que a iniciativa de organizar a praça com esse tipo de material partiu de um grupo de moradores do local, 17,5\% não souberam responder e 7,9\% indicaram que a ação partiu de um morador. Nenhum dos participantes apontou a "prefeitura" (poder público), "empresa" (iniciativa privada) ou "órgão externo a comunidade" (organizações não-governamentais), como agente mobilizador da proposta.Assim, reforça-se o reflexo do abandono por parte do poder público e a falta de investimento em espaços públicos de acesso livre (praças, jardins, parques), tanto pelo poder público, quanto pelo setor privado.

Essa ausência de políticas públicas voltadas para a revitalização desses equipamentos públicos de convívio e lazer impõe, sobretudo para a comunidade local, a necessidade de mobilização no sentido de transformação da realidade. Cardoso e Souza (2020) afirmam que as inquietações resultantes da percepção de um espaço abandonado pelo poder público e o desejo de criação de um espaço novo, diferenciado, atua como combustível para a articulação de moradores de áreas abandonadas, degradadas ou impactadas ambientalmente. As narrativas expressas, durante as entrevistas, pelas responsáveis diretas pela execução do projeto, corroboram com essa perspectiva:

C.S.: "A nossa primeira motivação foi contribuir com o meio ambiente e ter um espaço de qualidade de vida. Um espaço melhor e sabendo que a comunidade tem esse perfil, de cuidar. Eu acho que a gente melhorou, muito o ambiente teve essa interrelação ser humano e ambiente".

L.B.: "A gente queria que as crianças saíssem de casa e brincassem na rua, umas com as outras ou que tivessem um lugar organizado para brincar".

Por meio da articulação coletiva contínua, desde o ano de 2014, a comunidade colaborou para a mudança positiva da realidade da Praça da Amizade. 0 projeto serviu de 
inspiração para outras comunidades que iniciaram propostas semelhantes em outros espaços da cidade. 0 poder público reconheceu a iniciativa e, apesar de permeado de estratégias e discursos políticos, quatro anos após o início do projeto, instalou uma placa na referida praça, na qual se atribui o êxito da experiência à comunidade local (Figura 2).
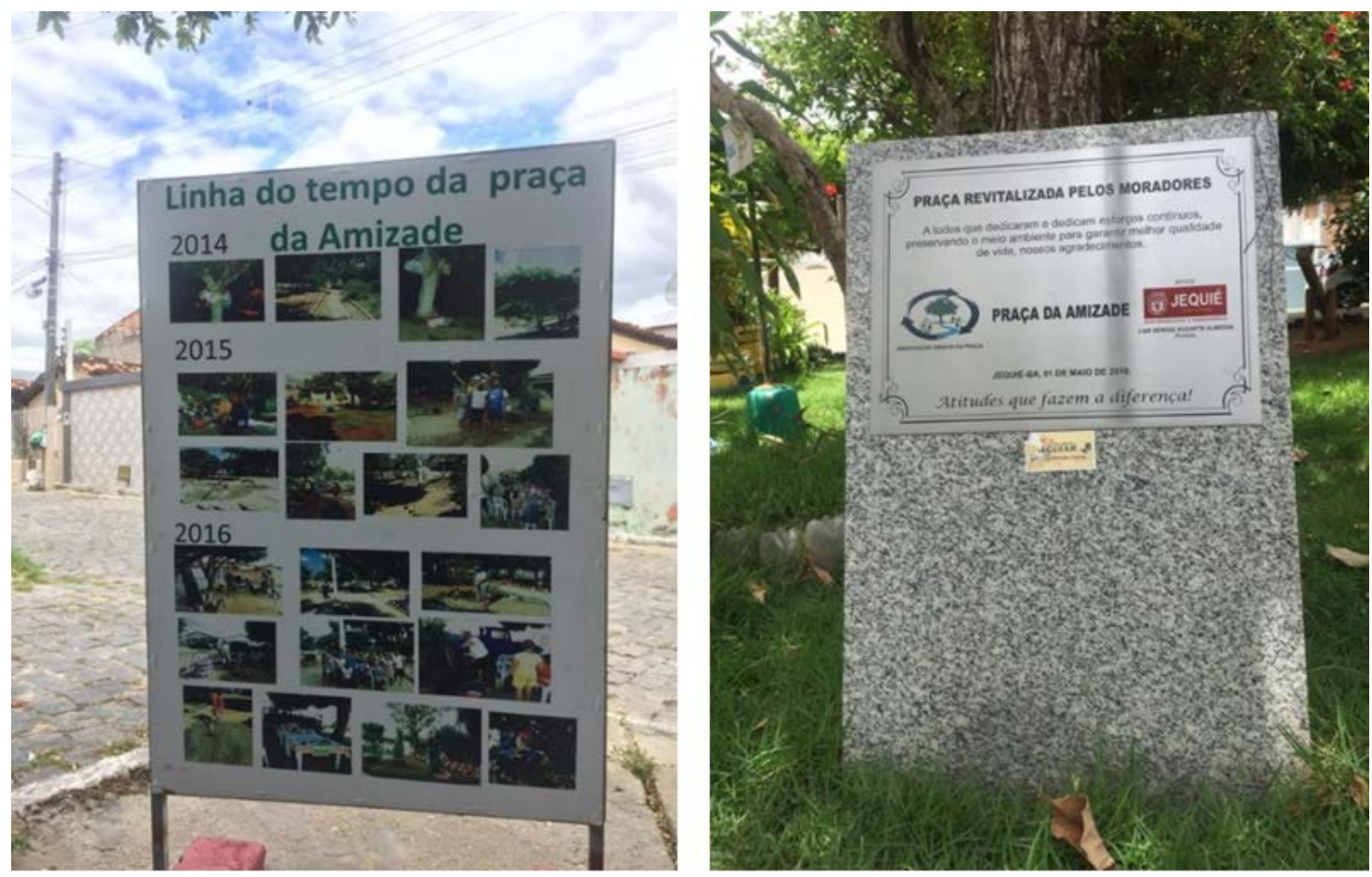

Figura 2. Linha do tempo do projeto desenvolvido na Praça da Amizade e placa instalada pelo poder público municipal. 2020.

\section{Praça da Amizade: percepção e paradigmas ambientais da/na comunidade}

Nas últimas décadas as questões ambientais têm se destacado, notadamente no que se refere ao questionamento de hábitos que colaboram para a degradação ambiental, bem como, na construção de proposições de novas formas de relação com a natureza e seus bens. Contudo, o cuidado com o ambiente ainda não se tornou uma prática universal, apesar de o discurso político-corporativo se apresentar permeado de narrativas a respeito da sustentabilidade, empregando termos como "economia verde", "emprego verde", "energias limpas", ecodesign, entre outros.

No imaginário social ainda prevalece visões antropocêntricas, que colocam a Natureza numa posição de subserviência, devendo ser dominada a serviço dos seres humanos, portanto uma visão dicotômica e binária da relação sociedade-Natureza (Krenak, 2019). Entretanto, a forma como cada indivíduo interage e percebe o meio que está inserido perpassa pela trajetória individual de cada ser. Cada sujeito projeta no ambiente suas ideias, crenças e valores para fazer a sua leitura, articulando uma linha de pensamento, atravessada por suas vivências.

A Praça da Amizade pode ser definida como um laboratório, espaço aberto a diversas possibilidades de estudos. Para alguns, local de refúgio, para outros ambientes de trabalho, apenas rota de passagem, ou ainda, lugar terapêutico, segundo narrativas dos participantes desse estudo. Essa diversidade de concepções e perspectivas evidencia 
também as diferentes visões a respeito da questão ambiental. Nesse contexto, buscou-se entender quais os paradigmas ambientais que predominam a partir da percepção da comunidade e como eles se expressam nos discursos dos participantes. Assim, esses discursos foram analisados à luz da classificação proposta por Silva (2011) e está representada na Tabela 2.

Tabela 2. Relação entre os paradigmas ambientais e o tipo de material utilizado na revitalização da Praça da Amizade.

\begin{tabular}{|c|c|c|c|c|c|}
\hline Antropocentrismo & $\%$ & Ecocentrismo & $\%$ & $\begin{array}{l}\text { Sustentabilidade- } \\
\text { Centrismo }\end{array}$ & $\%$ \\
\hline $\begin{array}{l}\text { Evita jogar o material } \\
\text { fora sobrecarregando o } \\
\text { lixão/aterro sanitário. }\end{array}$ & 9,5 & $\begin{array}{l}\text { Melhor forma de deixar o local } \\
\text { mais agradável e ao mesmo } \\
\text { tempo preservar o meio } \\
\text { ambiente ecologicamente. }\end{array}$ & 1,6 & $\begin{array}{l}\text { É uma forma de } \\
\text { reutilizar e reciclar } \\
\text { materiais que seriam } \\
\text { descartados (jogados } \\
\text { fora/lixo). }\end{array}$ & 77,8 \\
\hline- & - & - & $\begin{array}{l}\text { Baixo custo, sendo } \\
\text { assim uma forma } \\
\text { mais econômica de } \\
\text { organizar a praça. }\end{array}$ & 11,1 \\
\hline
\end{tabular}

A questão a respeito do porquê pela opção do uso de resíduos sólidos (material de sucata) na revitalização da praça, evidenciou a predominância do paradigma sustentabilidade-centrismo, pois 88,9\% respondeu que é uma forma de reutilizar e reciclar os materiais que seriam descartados e devido ao baixo custo, sendo uma forma mais econômica de organizar o espaço. Nota-se uma preocupação com a proteção do ambiente e voltada a práticas sustentáveis, no sentido da reutilização de materiais. A ideia de reciclar e reutilizar os materiais que seriam "jogados no lixo" está atrelada à noção do ambiente e da Natureza como finita, viva e sagrada, de forma que a mesma não consegue suportar os impactos causados pelos humanos. Contudo, a noção antropocêntrica também apresenta uma predominância, 9,5\%, que se relaciona com uma visão utilitarista da natureza.

No que concerne a importância da ação de qualificação da Praça da Amizade, o paradigma mais expressivo, do mesmo modo, é o da sustentabilidade-centrismo. Quando questionados sobre a importância de se cuidar da praça, a maioria dos participantes, $71,4 \%$, indicou a opção "Para uma relação harmônica dos seres humanos enquanto parte do meio ambiente" (Tabela 3). A ideia de que seres humanos e natureza dependem mutuamente um do outro, pode se relacionar com as interpretações que os participantes fazem sobre como suas ações afetam diretamente o ambiente, refletindo assim para práticas mais sustentáveis. De acordo com Silva et al. (2011) essa relação pode ser vista a partir de um inter-relacionamento mutuamente influenciado.

As respostas ilustr am, também, tendências teóricas que se situam no âmbito do antropocentrismo, ressaltando o viés utilitarista da relação sociedade-natureza como também, na mesma proporção, $14,3 \%$, uma inclinação ao econcetrismo, que enfatiza o meio ambiente sobre o ser humano. Assim, objetiva-se o binômio e a visão dicotômica no que compete a relação antrópica com a natureza. Ainda que essas tendências não prevaleçam, elas aparecem com frequência considerável nos discursos. 
Tabela 3. Percepção dos participantes sobre a importância do cuidado com a Praça da Amizade, de acordo aos paradigmas ambientais.

\begin{tabular}{|c|c|c|c|c|c|}
\hline Antropocentrismo & $\%$ & Ecocentrismo & $\%$ & $\begin{array}{l}\text { Sustentabilidade- } \\
\text { centrismo }\end{array}$ & $\%$ \\
\hline $\begin{array}{l}\text { Para deixar o bairro } \\
\text { mais bonito/agradável. }\end{array}$ & 14,3 & $\begin{array}{l}\text { Porque as praças são } \\
\text { espaços importantes } \\
\text { para meio ambiente. }\end{array}$ & 14,3 & $\begin{array}{l}\text { Para uma relação } \\
\text { harmônica dos seres } \\
\text { humanos enquanto } \\
\text { parte do meio } \\
\text { ambiente. }\end{array}$ & 71,4 \\
\hline $\begin{array}{l}\text { Porque as praças são } \\
\text { espaços importantes } \\
\text { para os seres humanos }\end{array}$ & 4,8 & - & - & - \\
\hline
\end{tabular}

A respeito do impacto da Praça da Amizade sobre a vida da comunidade, nota-se umaconvergência da percepção dos participantes na via do paradigma sustentabilidadecentrismo,pois $71,4 \%$ apontou ser importante tanto para os cidadãos, quanto para os outros seres vivos (Tabela 4). A percepção dos outros grupos situa-se, de modo equilibrado, numa proporção de 14,3\%, cada, no âmbito dos paradigmas ecocentrista e antropocentrista. Nesta, como sugere Silva (2014), a humanidade preserva a natureza para seu próprio benefício, o interesse estaria voltado, portanto, à manutenção da qualidade de vida humana e a sua existência.

Tabela 4. Percepção relacionada ao impacto da conservação da Praça da Amizade na vida dos usuários.

\begin{tabular}{|c|c|c|c|c|c|}
\hline Antropocentrismo & $\%$ & Ecocentrismo & $\%$ & $\begin{array}{l}\text { Sustentabilidade- } \\
\text { centrismo }\end{array}$ & $\%$ \\
\hline $\begin{array}{l}\text { Sim, pois ela é } \\
\text { importante para minha } \\
\text { qualidade de vida e da } \\
\text { minha família. }\end{array}$ & 14,3 & $\begin{array}{l}\text { Sim, pois ela é } \\
\text { importante para os } \\
\text { animais e para o meio } \\
\text { ambiente. }\end{array}$ & 14,3 & $\begin{array}{l}\text { Sim, pois a praça é } \\
\text { importante tanto } \\
\text { para os cidadãos, } \\
\text { quanto para os } \\
\text { outros seres vivos. }\end{array}$ & 71,4 \\
\hline
\end{tabular}

A noção de cuidado, proteção, gerência e relação de interdependência ser humano-Natureza, traços que prevaleceram na percepção da comunidade, pode estar relacionada com vínculos afetivo-temporal, grau de instrução e o sentimento de pertencimento em relação à praça. Destacam-se questões simbólicas e subjetivas, que são compreendidas por Tuan (1980) a partir do conceito de topofilia, que é o elo afetivo entre a pessoa e o lugar ou ambiente físico. Para o autor a topofilia é o mais alto grau de afetividade e pertencimento ao meio em que se está presente, percebendo-se todas as nuances, singularidades e potencialidades do mesmo.

Diante da análise dos dados, nota-se uma predominância do paradigma sustentabilidade-centrismo na percepção da comunidade, relativa à Praça da Amizade (Figura 3). Silva (2014, p.6) enfatiza que, "embora a sustentabilidade encontre-se fortemente vinculada à noção de desenvolvimento sustentável, começam a surgir contribuições que vão desvincular esses dois conceitos". Termos como sociedade sustentável, empresa sustentável e gestão sustentável, traduzem essa tendência que atua no sentido de separar as noções de desenvolvimento e sustentabilidade. Nesse interim, 
ganha destaque a ideia de que "não somente o desenvolvimento deve ser sustentável, mas todas as ações humanas, tanto em seus fins, como em seus meios".

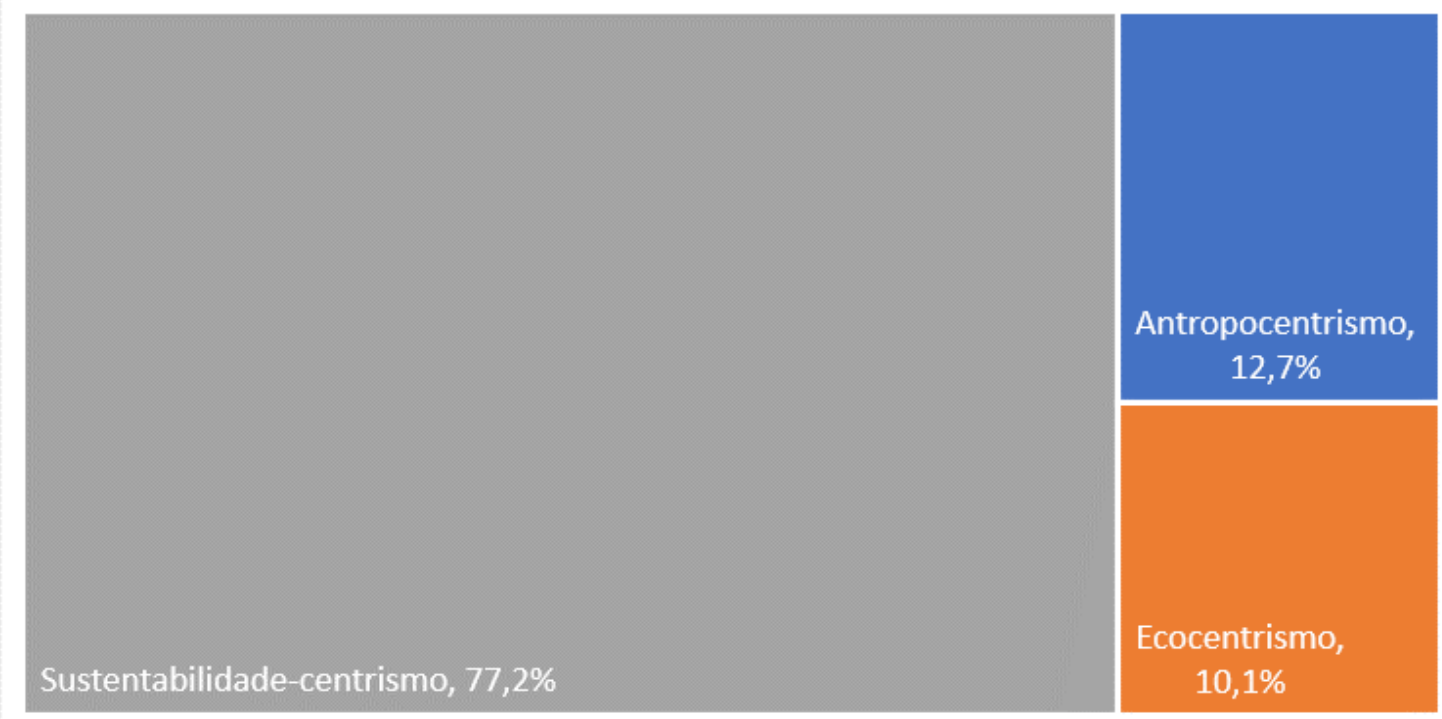

Antropocentrismo

Figura 3. Prevalência dos paradigmas ambientais na percepção da comunidade em torno da Praça da Amizade, Jequié-BA.

No aspecto responsabilidade social sobre a praça, $74,6 \%$ das pessoas que participaram do estudo responderam que "a responsabilidade deve ser compartilhada, tanto os moradores, quanto o poder público devem se empenhar",e apenas 9,5\% indicou que o poder público (Prefeitura) deve responder pela manutenção da praça, pois, "os impostos servem para manter serviços básicos como esses".

A noção de responsabilidade compartilhada remete ao conceito de governança ambiental na gestão dos espaços da cidade, o que aponta para futuras investigações que levem em conta essa questão. Como afirmam Jacobi e Sinisgalli (2012), a governança é um modo não hierárquico de governo, onde atores não-estatais, além de diversos segmentos participam na formulação e implementação de políticas públicas. Assim, no discurso dos participantes se evidencia uma consciência da comunidade relativa ao fato de que a gestão da praça pública deve contar com a colaboração de diferentes agentes sociais.

Por outro lado, a questão relativa à participação direta na qualificação da praça, seja através de cessão de material reciclável ou no envolvimento direto na execução do projeto, contrapõe essa visão, pois $65,1 \%$ informaram não ter doado nenhum tipo de material (enquanto que 34,9\% informou que sim, esses podem ser os moradores próximos da praça ou que residem há mais tempo, participando ativamente do projeto) e $73 \%$ informaram que não estiveram diretamente envolvidos na execução da ação.

Em relação às atuais necessidades que a praça apresenta para se tornar um lugar mais frequentado ou agradável para a comunidade, foi possível identificar cinco grupos de demandas na percepção comunitária. 0 primeiro grupo diz respeito à dimensão da gerência cotidiana e infraestrutura e destaca termos como iluminação, preservar, cuidado, 
organização, manutenção e limpeza, com 31 ocorrências. 0 segundo relaciona-se com a dimensão da publicação da experiência realizada através de termos como visibilidade, divulgação, realização de projetos e eventos, com 13 ocorrências. No terceiro grupo, dimensão da continuidade, destacam-se os termos: apoio ao projeto, colaboração, maior envolvimento da comunidade, ajuda e assistência, somando-se 11 ocorrências. A quarta dimensão, da segurança pública, enfatiza-se os termos rondas policiais e segurança, somando-se sete ocorrências.

De modo geral, na percepção da comunidade, o ambiente precisa de mais investimentos, manutenção, cuidado e limpeza. Embora os relatos dos moradores demonstrem que existe uma organização para a limpeza, não existe uma obrigação, sendo uma atividade voluntária, realizada de acordo com a disponibilidade de tempo dos moradores. Além disso, sobressai, mais uma vez, a ausência do poder público no cuidado com o referido espaço.

M.L.B. "Não sei, acho que ela tá tranquila, a limpeza que precisa ser com mais frequência. É uma terapia".

I.V. "Manter o trabalho de preservação e descrição das espécies e buscar levar o máximo de apelo cultural para o espaço. A praça é um lindo modelo que deveria ser replicado, porém existe nesse trabalho a importância da harmonia entre os envolvidos. Para a confecção de um projeto que integra tão bem natureza e humano deve se ter grande sensibilidade e compromisso. Em questão estrutural não imagino em que mais poderia se melhorar algo que já é tão belo, mas talvez atrelado a isso se houver a possibilidade ou permissão dos seus idealizadores, poderia (se não já houver) um vínculo entre esse espaço e as escolas, realização de programações educativas, culturais e o incentivo à ampliação da iniciativa com o desenvolvimento de trabalhos semelhantes em outras praças ainda sem visibilidade".

A dimensão da publicação, através da necessidade de divulgação do projeto, foi observada tanto pelos moradores ao redor da praça, quanto pela comunidade que a visita. A iluminação, dimensão da infraestrutura, foi apresentada como uma demanda local, uma vez que os moradores podem não se sentir seguros para visitar a praça à noite, devido à baixa luminosidade.

A noção de apoio ou assistência, dimensão da continuidade, geralmente apareceu direcionada ao poder público, evidenciando a falta de envolvimento do mesmo com a comunidade. A maior implicação foi observada nos participantes que residem nas proximidades da praça. A dimensão da segurança pública expressa demandas tanto dos moradores, quanto dos visitantes, por não se sentirem seguros no espaço, sobretudo em horários de pouco movimento e/ou sem iluminação natural.

J.K. "A praça precisa ser mais divulgada, pois ela fica numa área um pouco escondida. Acredito que a primeira impressão que ela deixa é muito marcante porque o transeunte não espera encontrar um lugar tão colorido, limpo e agradável no quarteirão. É um momento mágico, que te obriga a diminuir a velocidade dos passos e admirar cada detalhe da praça".

I.S. "Se o prefeito tivesse a bondade de pôr lâmpadas e ajudar na manutenção.Tudo aqui são os moradores que fazem".

J.A.P. "A ação do poder público em conjunto com os moradores". 
M.C.P. "Acredito que o poder público tem a obrigação primordial na realização destas tarefas. Contudo, pensando na melhoria do ambiente em que vivem aquelas pessoas, os moradores tomam a iniciativa e organizam seus espaços. Isso é motivado pela ausência governamental."

N.P. "Deixando mais segura, principalmente à noite”.

A.L.F. "Levar atrações para a praça; rondas frequentes; bancos; quiosques".

I.S. "Iluminação. Agora vamos repor as lâmpadas, assistência pública por causa da segurança”.

\section{Conclusões}

Os moradores em torno da praça demonstram maior conhecimento do projeto e laços de pertencimento mais evidentes, em relação aos moradores das adjacências. Esse fato também implica na forma, frequência e interação com o espaço. Os residentes mais próximos à Praça da Amizade usufruem com maior frequência desse espaço de convívio e tendem a cuidar ativamente do lugar. Constatou-se o apelo da comunidade para que os usuários da praça, seja a população residente ao redor, moradores das adjacências, visitantes ou o poder público, se empenhem na conservação, manutenção, divulgação e dinamização do projeto. Logo, aponta-se a necessidade de um maior envolvimento do poder público com as demandas dessa comunidade.

A atuação unilateral no processo de revitalização da praça poderia avançar, no sentido do estabelecimento de relações mais circulares, pautadas na cooperação entre comunidade, poder público, iniciativa privada e demais coletivos sociais. A noção de governança ambiental, apesar de não ter sido objeto teórico-metodológico desse estudo, cinge a discussão porquanto, se faz presente no discurso da comunidade, contempla a percepção ambiental dos sujeitos da pesquisa e aponta para a possibilidade de outras investigações científicas que contemplem a questão e aprofundem a análise.

A percepção ambiental da população em torno da praça evidenciou uma tendência voltada para as premissas do paradigma da sustentabilidade-centrismo. Enfatiza-se a percepção da relação sociedade-natureza pautada numa dialética da interdependência, através da qual a interação do ser humano com os recursos da natureza devem ser entendidos pela via da complementaridade, em detrimento da visão de dominação ou da prevalência de um elemento sobre o outro. Contudo, destaca-se também, ainda que de forma secundária, percepções arraigadas na visão ambiental antropocêntrica que coloca a natureza numa posição de subserviência, a partir da via utilitarista dos recursos naturais, como se estes fossem infinitos e o planeta inerte e, portanto, passivo de ser continuamente explorado.

A experiência de revitalização desenvolvida na Praça da Amizade, através do reaproveitamento de resíduos sólidos, chama atenção por sua densidade, capacidade de mobilização, envolvimento, participação social e continuidade ao longo do tempo. A ação caminha para uma década de existência, tornando-se objeto de estudos científicos, bem como, modelo para outras propostas na cidade. Mesmo diante da pouca atenção do poder público, a comunidade conseguiu manter o espaço minimamente adequado ao uso social.

\section{Conflito de interesses}

Os autores declaram não haver conflito de interesses. 


\section{Referências}

ABRELPE - Associação Brasileira de Empresas de Limpeza Pública e Resíduos Especiais. Panorama dos resíduos sólidos no Brasil 2017. São Paulo: ABRELPE, 2017.

ABRELPE - Associação Brasileira de Empresas de Limpeza Pública e Resíduos Especiais. Panorama dos resíduos sólidos no Brasil 2018/2019. São Paulo: ABRELPE, 2019.

Abreu, I. S.; Bussinguer, E. C. A. Antropocentrismo, ecocentrismo e holismo: uma breve análise das escolas de pensamento ambiental. Derecho y Cambio Social, n. 34, p. 1-11, 2013.

Bardin, L. Análise de conteúdo. Lisboa: Edições 70, 1977.

Brasil. Lei no 12.305, de 2 de agosto de 2010. Institui a Política Nacional de Resíduos Sólidos; altera a Lei no 9.605, de 12 de fevereiro de 1998; e dá outras providências. Disponível em: <http://www.planalto.gov.br/ccivil_03/_ato2007-2010/2010/lei/l12305. htm>. Acesso em: 02 abr. 2020.

Cabral, N. G.; Vargas, I. C.; Fagundes, I. C.; Santos, F. B.; Ribeiro, N. C. Do lixo à reciclagem: ressignificando saberes e fazeres. Diálogo, n. 31, p. 31-45, 2016. https://doi.org/ $10.18316 / 2238-9024.16 .22$

Cardoso, M.; Souza, A. L. S. Praças públicas comunitárias na "Cidade Sol” - Jequié-BA: territórios lúdicos de diálogos constante entre educação e democracia. Crítica Educativa, v. 6, n. 1, p. 1-19, 2020. https://doi.org/10.22476/revcted.v6.id459

Carneiro, A. R. S. Os espaços verdes na história do Recife. Paisagem e Ambiente, n. 19, p. 67-82, 2004. https://doi.org/10.11606/issn.2359-5361.v0i19p67-81

Cunha, A. S.; Leite, E. B. Percepção ambiental: implicações para a educação ambiental. Sinapse Ambiental, p. 66-79, 2009. Disponível em: <http://www4.pucminas.br/ graduacao/cursos/arquivos/ARE_ARQ_REVIS_ELETR20090930145741.pdf>. Acesso em: 02 abr. 2020.

Cunha, J. S.; Fernandes, F. M.; Silva, M. S.; Santos, E. F. S.; Leal, R. B. R. Estratégias de mobilização e participação popular no sistema de coleta seletiva de lixo em Jequié-BA: um estudo de caso. Revista Científica da Escola de Administração do Exército, v. 2, p. 79-95, 2008.

Godinho, R. E. Nova metodologia de projeção da população flutuante. São Paulo: ABEP, 2008.

IBGE - Instituto Brasileiro de Geografia e Estatística. Censo Brasileiro de 2010. Rio de Janeiro: IBGE, 2010.

Jacobi, P. R.; Sinisgalli, P. A. A. Governança ambiental e economia verde. Ciência \& Saúde Coletiva, v. 17 , n. 6 , p. 1469-1478, 2012. https://doi.org/10.1590/S141381232012000600011

Krenak, A. Ideias para adiar o fim do mundo. 1. ed. São Paulo: Companhia das Letras, 2019.

Marchi, L. M.; Pezzini, C. Fundamentos arquitetônicos: revitalização da Praça Santos Dumont. Anais do 13을 Encontro Científico Cultural Interinstitucional, FAG, Santa Helena, Paraná, 2015.

Martins, G. A. F.; Silva, J. G.; Gomes, G. O. A função das praças públicas no meio ambiente urbano: o caso da Praça Esportiva Belmar Fidalgo de Campo Grande-MS. FIEP Bulletin On-Line, v. 84, 2014. 
Melazo, G. C. Percepção ambiental e educação ambiental:uma reflexão sobre as relações interpessoais e ambientais no espaço urbano. Olhares \& Trilhas, n. 6, p. 45-51, 2005.

Merleau-Ponty, M. Fenomenologia da percepção. 2. ed. São Paulo: Martins Fontes, 1999.

Pacheco, E.; Silva, H. P. Compromisso epistemológico do conceito de percepção ambiental. Anais do II Seminário Áreas Protegidas e Inclusão Social, 2006.

Palma, I. R. Análise da percepção ambiental como instrumento ao planejamento da educação ambiental. Porto Alegre: Universidade Federal do Rio Grande do Sul, 2005. (Dissertação de mestrado).

Panquestor, E. K.; Riquetti. N. K. Percepção ambiental, descaso e conservação: uso da geoinformação no estudo de áreas verdes públicas em Carangola-MG. 2008. Anais do IV Encontro da Associação Nacional de Pós-Graduação e Pesquisa em Ambiente e Sociedade, Brasília, 2008.

Silva, S. S. Proposta de um modelo de análise do comprometimento com a sustentabilidade. Ambiente \& Sociedade, v. 17, p. 35-54, 2014. https://doi.org/10.1590/ S1414-753X2014000300004

Silva, S. S.; Reis, R. P.; Amâncio, R. Paradigmas ambientais nos relatos de sustentabilidade de organizações do setor de energia elétrica. Revista de Administração Mackenzie, v. 12, n. 3, p. 146-176, 2011. https://doi.org/10.1590/S1678-69712011000300007

Sousa, C. A. F.; Almeida, S. V. N. C.; Silveira, J. A. R. Espaços livres públicos e proteção ambiental:um estudo de caso sobre as praças públicas da zona sul da Cidade de João Pessoa, PB. Periódico Técnico e Científico Cidades Verdes, v. 4, n. 9, p. 102-113, 2016. https://doi.org/10.17271/23178604492016

Tuan, Y.-F. Topofilia: um estudo da percepção, atitudes e valores do meio ambiente. São Paulo: DIFEL, 1980.

Informação da Licença: Este é um artigo Open Access distribuído sob os termos da Licença Creative Commons Attribution, que permite uso irrestrito, distribuição e reprodução em qualquer meio, desde que a obra original seja devidamente citada. 